\title{
Dielectric Elastomer Generator for Electromechanical Energy Conversion: A Mini Review
}

\author{
Kui Di ${ }^{1,2}\left(\mathbb{D}\right.$, Kunwei Bao ${ }^{1,2}$, Haojie Chen ${ }^{1,2}$, Xinjun Xie ${ }^{1,2}$, Jianbo Tan ${ }^{1,2}$, Yixing Shao ${ }^{1,2}$, Yongxiang Li ${ }^{1,2}$, \\ Wenjun $X_{i a}{ }^{1,2}$, Zisheng $X u^{1,2, *}$ and Shiju $E^{1,2, *}$ \\ 1 College of Engineering, Zhejiang Normal University, Jinhua 321004, China; dikui70@zjnu.edu.cn (K.D.); \\ bkw_0201@zjnu.edu.cn (K.B.); 1335224231@zjnu.edu.cn (H.C.); 1653004525@zjnu.edu.cn (X.X.); \\ 1974179451@zjnu.edu.cn (J.T.); syx0717@zjnu.edu.cn (Y.S.); lyx@zjnu.edu.cn (Y.L.); wjxia@zjnu.edu.cn (W.X.) \\ 2 Key Laboratory of Urban Rail Transit Intelligent Operation and Maintenance Technology \& Equipment of \\ Zhejiang Province, Zhejiang Normal University, Zhejiang 321005, China \\ * Correspondence: zishengxu@zjnu.edu.cn (Z.X.); esx_2001@zjnu.cn (S.E.)
}

Citation: Di, K.; Bao, K.; Chen, H.; Xie, X.; Tan, J.; Shao, Y.; Li, Y.; Xia, W.; $\mathrm{Xu}, \mathrm{Z}$.; E, S. Dielectric Elastomer Generator for Electromechanical Energy Conversion: A Mini Review. Sustainability 2021, 13, 9881. https:// doi.org/10.3390/su13179881

Academic Editors: Peihua Yang, Jia Li and Tianpeng Ding

Received: 7 July 2021

Accepted: 29 August 2021

Published: 2 September 2021

Publisher's Note: MDPI stays neutral with regard to jurisdictional claims in published maps and institutional affiliations.

Copyright: (c) 2021 by the authors. Licensee MDPI, Basel, Switzerland. This article is an open access article distributed under the terms and conditions of the Creative Commons Attribution (CC BY) license (https:/ / creativecommons.org/licenses/by/ $4.0 /)$.

\begin{abstract}
The dielectric elastomer generator (DEG) has attracted attention in converting mechanical energy into electrical energy, due to its high energy density, fast response, and light weight, which together make DEG a promising technology for electromechanical conversion. In this article, recent research papers on DEG are reviewed. First, we present the working principles, parameters, materials, and deformation modes of DEG. Then, we introduce DEG prototypes in the field of collecting mechanical energy, including small-scale applications for wind energy and human motion energy, and large-scale applications for wave energy. At the end of the review, we discuss the challenges and perspectives of DEG. We believe that DEG will play an important role in mechanical energy harvesting in the future.
\end{abstract}

Keywords: dielectric elastomer generator; wind energy; wearable; wave energy

\section{Introduction}

In recent years, researchers have pursued the study of methods that can convert mechanical energy including wind, wave, and human motion energy into electrical energy. At present, there are five main transduction approaches to converting mechanical energy into electrical energy, including electromagnetic (ES) [1], triboelectric (TE) [2], piezoelectric (PE) [3], reverse electro wetting [4], and dielectric elastomer (DE) [5]. Among them, DE is an electroactive polymer material that can work in different situations, such as in actuator, sensor, and generator [6,7]. DE generator (DEG) has shown advantages in converting low frequency mechanical energy into electrical energy thanks to their high energy density, large deformation, fast response, and light weight.

The DEG was first posed by Pelrine in 2001 [8]. It is a capacitor that can convert energy through deformation. DEG has achieved high-efficiency electromechanical conversion (theoretical values up to $80-90 \%$ [8]), and high energy density (theoretical values up to $1.7 \mathrm{~J} / \mathrm{g}$ [9] and experimental values up to $0.78 \mathrm{~J} / \mathrm{g}$ [10]). The high energy density of DEG is at least an order of magnitude higher than electromagnetic and piezoelectric generators [11]. Additionally, DEG can harvest energy in different situations, ranging from small scales such as human motion and wind energy to large scales such as wave energy [12-15].

In the following, some parameters of DEG such as output performance, materials, and deformation modes will be presented. In addition, the discussion of energy harvesting based on DEG will be focused mainly on wind, human motion, and wave energy. Conclusions and challenges to future trends in DEG will be discussed at the end. 


\section{Dielectric Elastomer Generator}

\subsection{Energy Conversion Principle}

The structure of a DEG is similar to a sandwich, consisting of DE film and compliant electrodes coated on both sides. It can convert mechanical energy into electrical energy from the stretched state to released state [16]. There are three energy collecting modes for a DEG in one cycle, for constant charge $Q$, constant voltage $V$ and constant electric field strength E. Research [17] has shown that constant charge $Q$ can gain more energy in one cycle, which is often used in the application of DEG energy harvesting.

The energy conversion process for DEG can be classified into four steps (step 1, step 2, step 3, and step 4), as illustrated in Figure 1a [18,19].

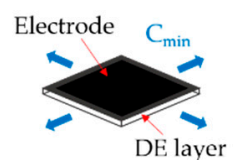

(I)

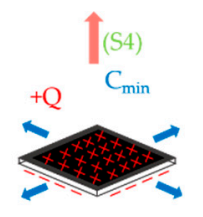

(IV)

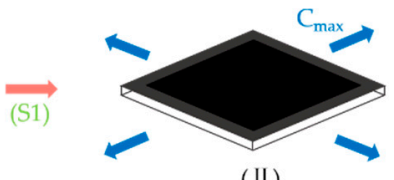

(II)

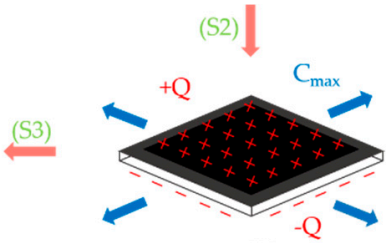

(III)

(a)

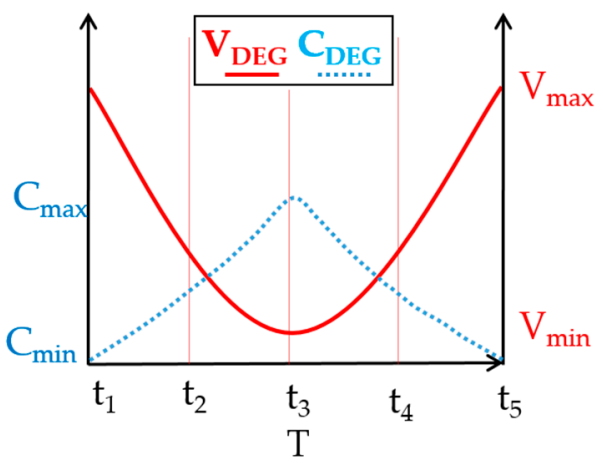

(b)

Figure 1. (a) Four working steps of a DEG. (b) Waveform for one cycle of DEG on a capacitance-voltage.

Step 1: At initial state $\mathrm{I}$, the capacitance of DEG is minimum $\left(C_{\min }\right)$. Next, DEG is stretched by an external mechanical force, leading to state II, where its capacitance is maximum $\left(C_{\max }\right)$. Its capacitance can be calculated through the equation:

$$
C=\frac{\varepsilon_{r} \varepsilon_{0} S}{d}
$$

where, $\varepsilon_{r}, \varepsilon_{0}$ represent the relative dielectric constant and the absolute dielectric constant $\left(8.85 \times 10^{-12}\right.$ F.m $\left.{ }^{-1}\right) ; S$ and $d$ are the area and thickness of the DEG.

Step 2: Charge $Q$ is injected into two electrodes by a bias power source, transferring electrical energy to DEG by turning on a bias voltage, leading to state III $\left(C_{\max }\right)$. Then, removing the source, the amount of charge in DEG remains constant.

Step 3: The mechanical force is then removed and the DEG is relaxed to state $\operatorname{IV}\left(C_{\min }\right)$, increasing the DEG thickness and decreasing the electrode area. The electrical energy of DEG will increase as unlike charge is pulled further apart in different electrodes, and like 
charge is pushed together in the same electrode. The amount of generated energy can be calculated according to the following equation:

$$
\Delta E=E_{2}-E_{1}=\frac{1}{2}\left(C_{2} V_{2}^{2}-C_{1} V_{1}^{2}\right)
$$

The amount of charge in DEG remains constant. According to the equation $\mathrm{Q}=C_{2} V_{2}=C_{1} V_{1}$ [17], the capacitance and voltage of DEG changing in one cycle are depicted in Figure 1b. Thus, Equation (2) can be rewritten as:

$$
\Delta E=\frac{1}{2}\left(C_{2} V_{2}^{2}-C_{1} V_{1}^{2}\right)=\frac{1}{2} C_{1} V_{1}^{2}\left(\frac{C_{1}}{C_{2}}-1\right)
$$

where $S_{1}, d_{1}$, and $V_{1}$ are the area, thickness, and bias voltage of DEG in state III, and $S_{2}$ and $d_{2}$ are the area and thickness of DEG in state IV. When the DEG is stressed or released, we usually assume that the volume of DEG will remain unchanged, $V=S_{1} \times d_{1}=S_{2} \times d_{2}$. According to Equation (1), Equation (3) can be rewritten as:

$$
\Delta E=\frac{1}{2} \frac{\varepsilon_{\mathrm{r}} \varepsilon_{0} S_{1}}{d_{1}} V_{1}^{2}\left(\frac{S_{1}}{S_{2}} \times \frac{d_{2}}{d_{1}}-1\right)=\frac{1}{2} \frac{\varepsilon_{\mathrm{r}} \varepsilon_{0} S_{1}}{d_{1}} V_{1}^{2}\left(\frac{S_{1}^{2}}{S_{2}^{2}}-1\right)
$$

Step 4: This is called the discharging step, and the gained electric energy is collected.

\subsection{Output Performance}

The output performance of DEG in one cycle is reflected by two important parameters: energy density and electromechanical conversion efficiency. Energy density $\left(E_{\text {density }}\right)$ is the ratio of the generated energy to the material's mass (m), and energy conversion efficiency $(\eta)$ is the ratio of the generated energy to $W_{\text {mech }}$ [20]. $W_{\text {mech }}$ is input mechanical energy in one cycle, which can be calculated by the force-displacement integral curve of DEG shown in Figure 2a. $E_{d e n s i t y}, W_{\text {mech }}$, and $\eta$ can be calculated according to the following equation:

$$
\begin{gathered}
E_{\text {density }}=\frac{\Delta E}{m} \\
W_{\text {mech }}=\int_{S_{0}}^{S_{1}}\left(F_{\text {stretch }}-F_{\text {release }}\right) d S \\
\eta=\frac{\Delta E}{W_{\text {mech }}}
\end{gathered}
$$

In past years, great efforts have been made to improve the energy density and electromechanical conversion efficiency of DEG. For example, Fan [21] improved the output performance of DEG by increasing the cycle period and decreasing the pre-stretch ratio. Zhou [22] found that conversion efficiency could be raised by avoiding loss of tension. Mckay [23] has integrated a stretchable circuit within the membrane and achieved an energy density of $10 \mathrm{~mJ} / \mathrm{g}$ at the same conversion efficiency of $12 \%$. An energy density of $18.9 \mathrm{~mJ} / \mathrm{g}$ with energy conversion efficiency of $18.3 \%$ was achieved with charging-whilestretching mode by Wang [24]. Huang [25] achieved an energy density of $560 \mathrm{~mJ} / \mathrm{g}$ with an efficiency of $27 \%$ using an equibiaxial mechanical loading configuration. The maximum reported energy density of $780 \mathrm{~mJ} / \mathrm{g}$ was obtained by optimizing the triangular scheme [10]. As we can see from Figure $2 b$, it was operated under four mechanisms of failure mode condition [26-29]: electrical breakdown (EB), electromechanical instability (EMI), material rupture (MR), and loss of tension (LT). They are the physical operating limits of a working DEG. Jiang [30] obtained an energy density of $130 \mathrm{~mJ} / \mathrm{g}$ and a maximum conversion efficiency of $40 \%$ by combining equibiaxial pre-stretch to cone stretching and controlling the input bias voltage pre-stretch ratio. 


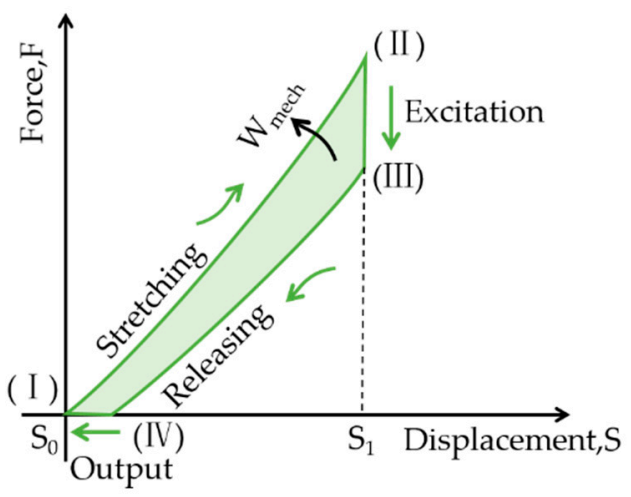

(a)

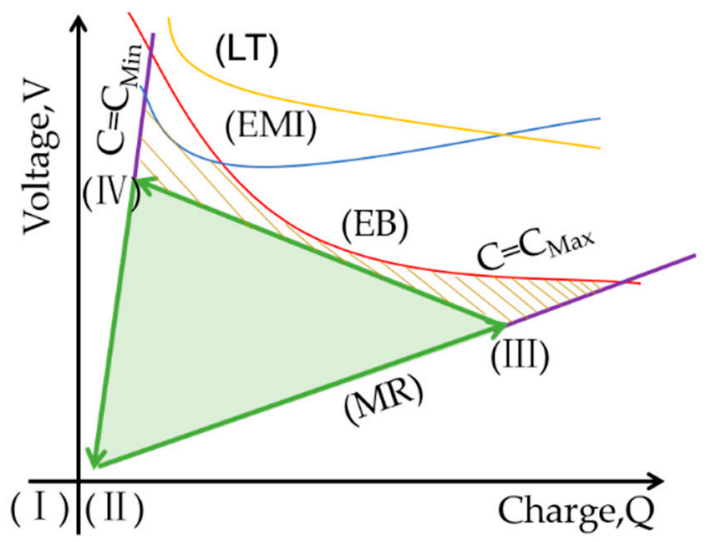

(b)

Figure 2. (a) The force-displacement plot of DEG and the area enclosed by curve I-II-III-IV represent the input mechanical energy $\left(W_{\text {mech }}\right)$ in one cycle. (b) Voltage-charge plot of the DEG operating cycle, which also shows the four failure modes such as electromechanical instability (EMI), electrical breakdown (EB), mechanical rupture (MR) and loss of tension (LT).

All of these advances ensure a brilliant future for DEG as an electromechanical conversion system. The energy density is significantly enhanced; however, it is still lower than the theoretical maximum value of $1.7 \mathrm{~J} / \mathrm{g}$ [9]. This is due to the viscoelasticity effects and leakage current of DEG [31,32]. Due to low viscoelasticity and high leakage current, it is difficult to reach DEG's theoretical maximum energy density of $1.7 \mathrm{~J} / \mathrm{g}$. Currently, many investigations have been focused on the energy density of DEG while neglecting viscosity and leakage current, resulting in differences between experimental results and theoretical values. Of course, the generated energy of DEG is influenced by other factors as well, such as dielectric strength and temperature [33-35]. When calculating the values, we should consider all factors comprehensively.

\subsection{Materials}

In recent years, a large number of materials for use in DEG have been tested, and three in particular hold promise: acrylic, rubber, and silicone elastomer [36]. The output performance of DEG strongly relies on the properties of DE materials. DE materials are a crucial consideration in improving the output performance of DEG. The influences of material properties are as follows: (1) large deformation, which can cause the capacitance of DEG to vary over a wide range and enable the generation of more energy. This depends on the elastic modulus and elongation at break of material. (2). Break-down dielectric 
strength and relative dielectric constant affect the maximum operating voltage and energy density of DEG. (3). Energy loss is impacted by conductivity and hysteresis loss.

The material properties of acrylic (VHB 4905) [37], rubber (THERANBAND YELLOW 11726) [37], and silicone elastomer (LR3043/50) [38,39] are shown in Table 1. They include dielectric strength (break-down electric field), relative dielectric constant, shear modulus, hysteresis loss, max stretch ratio (maximum stretch to minimum stretch), and DE conductivity.

Table 1. Material parameters of three DE materials.

\begin{tabular}{lccc}
\multicolumn{1}{c}{ Property } & VHB $\mathbf{4 9 0 5}$ & $\begin{array}{c}\text { THERABAND } \\
\text { YELLOW11726 }\end{array}$ & LR3043/500 \\
\hline Unstretched Dielectric & 66.2 & 97.1 & 121 \\
Strength E [kV/mm] & 4.14 & 2.72 & 2.7 \\
Relative dielectric constant, $\varepsilon_{\mathrm{r}}$ & 16.92 & 328.18 & 380 \\
Shear modulus $\mu_{0}[\mathrm{kPa}]$ & 14.64 & 8.99 & $2-4$ \\
Hysteresis loss [\%] & 7.4 & 4.4 & 5.8 \\
Max stretch, $\frac{\lambda_{\text {Max }}}{\lambda_{\min }}$ & $5.7 \times 10^{-1}$ & $6.4 \times 10^{-2}$ & $1.7 \times 10^{-5}$ \\
Conductivity, at low field & & & \\
$\kappa_{\mathrm{d}}[\mathrm{pS} / \mathrm{m}$ ] & &
\end{tabular}

The acrylic elastomers VHB (4910 or 4905) from 3M have been largely used in DEG and have shown excellent output performance $[9,29,31]$. VHB is usually pre-strained in the experiment, which can significantly improve the output of DEG. For example, pre-straining can raise the breakdown strength of DEG [28], and it can also raise the response speed of DEG. The main disadvantage of acrylic is its high viscoelasticity, which results in a slow response to mechanical signals, limiting its conversion efficiency [40].

DEG based on rubber has higher fracture energy and dielectric strength than common acrylic elastomer, and enables clean, low-cost generation of electricity, which has achieved an energy density of $369 \mathrm{~mJ} / \mathrm{g}$ [41]. It has been found that natural rubber outperforms acrylic at strains of less than 15\% [9]. A characteristic of natural rubber is that its relative dielectric constant does not change with stretch ratio [42]. However, it is difficult to change the shape of rubber due to its large elastic modulus.

Silicone elastomer is a promising material for DEG due to its long-term stability [43]. Silicone elastomer possesses lower viscous loss and responds faster than acrylic elastomer [44], allowing operation at higher frequencies with lower mechanical energy loss. Silicone elastomers can also be operated over a wide temperature range, making them suitable for broader applications. DE actuator using silicone elastomer has been reported to obtain maximum lifetimes over $10^{9}$ cycles without failure [45]. Using silicone elastomer achieved an energy density up to $173 \mathrm{~mJ} / \mathrm{g}$ with conversion efficiency of 30\% [46]. However, silicone elastomer has a relative low dielectric constant than other elastomers, resulting in low energy density [47]. Silicone elastomer is more expensive than acrylic and rubber, limiting its application.

There are many methods to improve the output performance of materials. For example, we can regulate the stress-strain response of the elastomers, which can reduce hysteresis loss. We can also increase the relative dielectric constant [48,49], which can raise the energy density of a material. The output performance of materials is crucial for DEG applications. Improving the output performance of DE materials through modification is a challenge for the large-scale application of DEG and should attract the attention of researchers.

\subsection{Deformation Modes}

The deformation modes of DEG have an important influence on electromechanical energy conversion. As the electrical energy stored in DEG is proportional to capacitance, we see from Equation (3) that increasing the energy of DEG depends on how much capacitance 
can be changed in one cycle. The capacitance strongly depends on deformation, as the capacitance of the stretched DEG increases with larger area and reduced thickness.

The deformation modes of DEG can be divided into in-plane deformation mainly including equibiaxial, pure shear, and uniaxial stretching [50], and out-of-plane deformation [51] mainly including conical and circular inflatable modes [52]. An overview of DEG deformation modes is shown in Figure 3.

So-called uniaxial extension stretches DEG along the direction of force (Figure 3a). However, it will shrink in the transverse direction when DEG is stretched in the longitudinal direction, which results in a small capacitance change [53]. The pure shear stretching is subjected to uniaxial tensile force, with transversal stretch held constant, so as to cause deformation in the longitudinal direction. There is little necking on the sides of the DEG (Figure $3 b$ ). A large height-to-width ratio (more than 20) is employed to acquire pure-shear experimental results [54], or we can fix the side that is not stretched [55]. The pure shear stretching can prevent loss of tension, cause larger changes in capacitance, and is easily implemented in practice [56].

The equibiaxial deformation is uniform stretching of DEG in each direction [20] (Figure 3c), which maximizes capacitance variation. Uniaxial, pure-shear, and equibiaxial stretching deformation change the capacitance in proportion to the first, second, and fourth power of the stretch ratio. Koh [9] predicted that the maximum energy density could be obtained by using equibiaxial deformation. Equibiaxial loading causes uniform deformation over the area, which prevents mechanical stress that may result in premature failures. However, the device is complex, and it is a challenge to capture energy using equibiaxial stretching.

The conical DEG model mainly consists of a fixed frame, mobile frame, and adhesive DEG (Figure 3d). When the mobile frame is moving, its capacitance is changing accordingly. In this mode, stretching mainly takes place along the midline direction of the fixed frame, and the stretching is kept constant in the circumferential direction, which is similar to pure-shear tension. The structure of the cone DEG is simple, and it is convenient for the capture of mechanical energy from environment. However, the energy density of a cone DEG is lower, usually one order of magnitude lower than an equibiaxial deformation DEG [24]. Therefore, it is necessary to improve its energy harvesting performance.

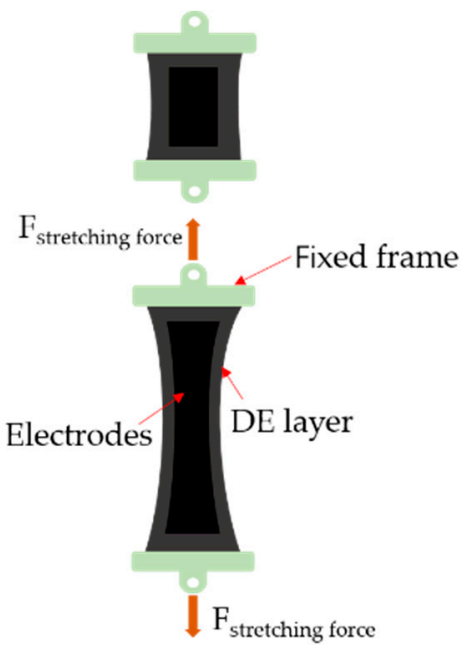

(a)

Figure 3. Cont. 


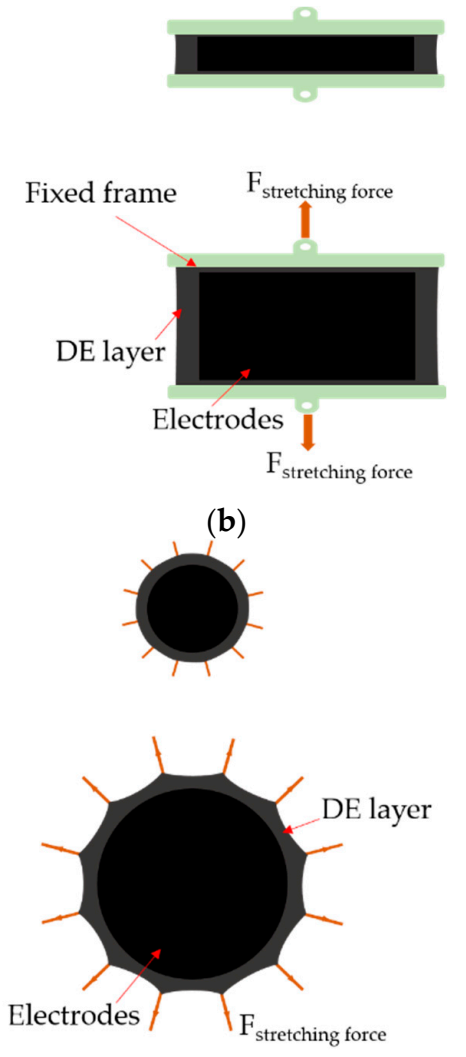

(c)
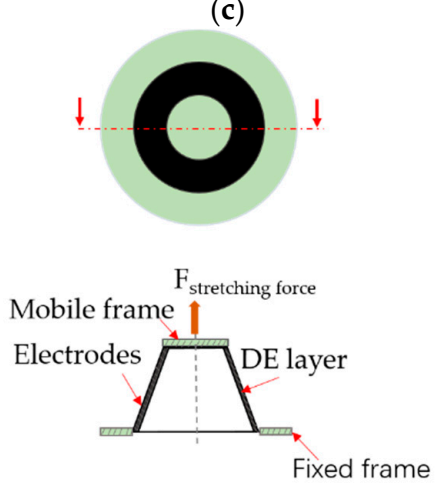

(d)
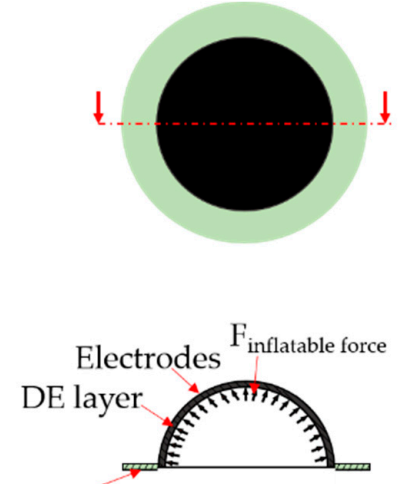

Fixed frame

(e)

Figure 3. The deformation modes of DEG. (a) uniaxial DEG; (b) pure shear DEG; (c) equibiaxial DEG; (d) cone DEG; (e) circular inflatable DEG. 
The circular inflatable DEG uses pressure difference between inside and outside of the DEG to harvest energy (Figure 3e). Its capacitance increases with expansion of the DEG. The radial stress is approximately equal to circumferential stress in the top region, which can be regarded as equibiaxial deformation. It is predicted to generate the higher energy of conversion [57]. However, the internal air flow is unstable, which has an influence on the output performance of this DEG. This drawback should be solved when circular inflatable deformation is used in practical applications.

Other deformation modes have been studied in addition to the above, such as stack, vibro-impact, and pendulum deformation [58-60]. The deformation modes not only affect energy output, but change the failure modes of DEG [50]. Therefore, all of these factors should be considered comprehensively when designing a DEG.

\section{Dielectric Elastomer Generator for Energy Harvesting}

Renewable energy harvesting is a central theme of modern scientific research. As discussed above, DEG has shown its potential in energy harvesting owing to its large deformability, high energy density, and electromechanical conversion efficiency. In the following section, we will review research on the use of DEG for collecting sustainable energy such as wind, human motion, and wave energy.

\subsection{Wind Energy}

In recent years, the conversion of wind energy into electrical energy has attracted much attention. To date, some researchers have studied DEG using wind energy as the input source. In the following, we will review some investigations of wind energy harvesting.

In 2017, Yurchenko [61] proposed the vibro-impact (VI) DEG system. Afterward, many researchers further investigated VI-DEG [62-64], which can harvest vibration energy from the environment. Based on the principle, Zhang [65] designed a device for use in collecting wind energy. Its structure is shown in Figure $4 \mathrm{a}, \mathrm{b}$. When the wind flows through the blades, they rotate accordingly. The inner ball will move between two DEGs under the action of gravity and centrifugal force. If the wind speed and the quality of the ball meet certain conditions, the ball will impact DEG on both sides, which will change its deformation. Thus, wind energy is converted into electrical energy according to mechanical-electrical principles of DE materials. The author has studied the performance of VI DEG collecting wind energy through numerical simulations [65]. The results showed that the performance of VI DEG energy collection is significantly affected by wind speed. However, the results have not been validated through experiments.

(a)

(b)

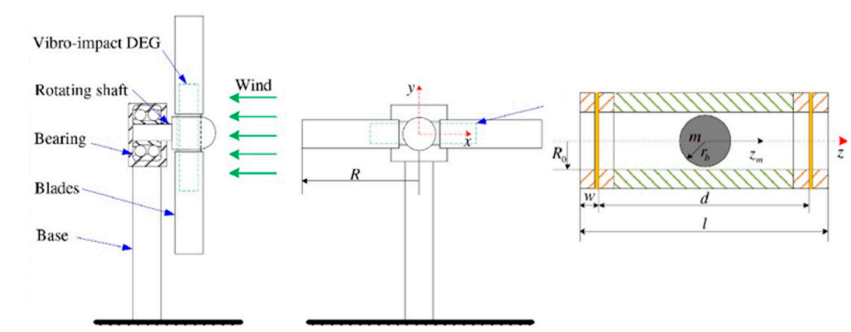

(c)

(d)
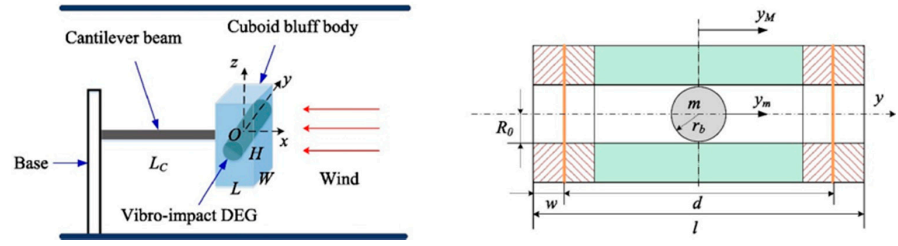

Figure 4. (a) Diagram of a wind energy harvester and (b) the structure of embedded VI DEG corresponding to (a). (c) The system structure and (d) the scheme of DEG corresponding to (c). 
Lai [66] has studied another wind energy harvester based on VI DEG. As seen in Figure 4c,d, the DEG is embedded into a cuboid bluff body. The bluff body will drive the VI DEG to move under the flow of wind. The dynamic and electrical outputs of the system under different wind speeds were studied through numerical simulations.

Through numerical simulations reported previously, the DEG only collects wind energy in a specific wind speed range. In order to realize the application of DEG collecting wind energy, much work needs to be done. For example, further innovations in structural design are urgent.

\subsection{Human Motion Energy}

People consume significant amounts of energy walking or running every day. The challenge of collecting human motion energy is an interesting and important research area. Human motion energy can be used in wearable electronic devices (such as sensors for human health monitoring) that can be driven in the milliwatt range. Thus, it is possible that wearable electronic devices will be battery-free some day. It is suitable to collect human energy from walking, kneeling, and elbow bending [67] using DEG owing to its electromechanical conversion principle. It will be quite compelling to use such energy in the future.

The angle of the thigh and calf varies from 50 to $60^{\circ}$ when a person is walking, and from 50 to $120^{\circ}$ when a person is running [68]. If a DEG is integrated into a kneepad and applied to the knee, the DEG will undergo large deformations when people are walking or running; its structure is similar to Figure 5a. Using this principle, Jean [69] has developed a DEG integrated into a knee pad that can harvest $1.5 \mu \mathrm{J}$ energy at $1 \mathrm{~Hz}$. If the kneepad area and bias voltage are increased, the amount of harvested energy will increase accordingly. Slade [70] has developed a modified commercial knee brace that collects energy during ambulation, and average output power of $3.13 \mu \mathrm{W}$ can be obtained.

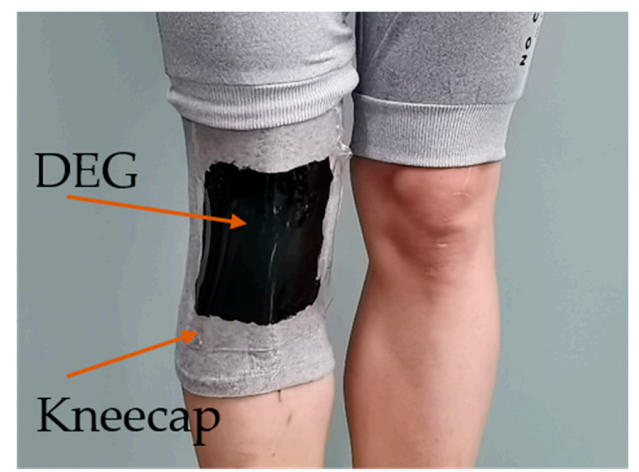

(a)

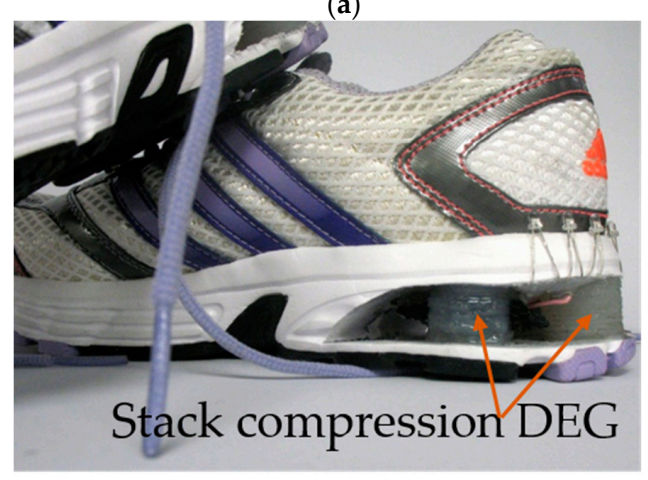

(b)

Figure 5. The pictures illustrate human motion energy harvesting based on DEG. (a) Knee winding energy harvesting. (b) Heel-strike energy harvesting device based on stack DEG (University of Auckland). 
The heel is impacted and compressed continuously when a person is walking, and the shape will change due to the action of gravity. Kornbluh [71] et al. have designed a DEG coupled into the heel, which can convert human motion energy into electrical energy through compression and relaxation of the heel in each step. Maximum energy output of $0.8 \mathrm{~J}$ can be obtained in one cycle. Mckay [72] has shown a heel generator using DEG (Figure 5b). The LEDs on his shoe were powered on, without cumbersome external circuitry, when he walked up and down. Output performance of $30-40 \mathrm{~mW}$ could be achieved when the area of acrylic film was only one square centimeter.

Even now, there are still many disadvantages in using DEG to collect human motion energy, such as the need for a bias voltage source and the lack of practical applications for harvesting human motion energy. However, DEG is still an outstanding candidate for the collection of energy from human motion due to its advantages. We believe that DEG will be able to power wearable electronics in the future when we are walking or running.

\subsection{Wave Energy}

Wave energy is considered to be a clean and renewable resource that is abundant and able to meet heavy demand for electricity worldwide. In recent years, the development and utilization of wave energy have gained much attention. Traditional wave energy converter (WEC) prototypes are based on electromagnetic technologies, which are expensive, complex, and can be corroded by sea water easily, limiting their commercialization. A DEG can be applied to the power take-off (PTO), as a critical part of a DE-WEC that may be cheaper, simpler, and more corrosion-resistant than traditional PTOs. More importantly, it can potentially achieve high output performance with low-frequency waves $(\leq 3 \mathrm{~Hz})$. This section reviews the prototypes and research on harvesting wave energy based on DE.

An innovative WEC resembling a buoy was designed by Chiba [73]. Its structure is similar to that shown in Figure 6a. The device mainly consists of circular ring flotation foam, proof mass $(62 \mathrm{Kg}$ ), and DE rolls (diameter of $30 \mathrm{~cm}$ and a stretched condition length of $20 \mathrm{~cm}$ ). The mechanical structure connecting the proof mass with the DE rolls is very simple. The DE rolls are stretched and compressed when the proof mass floats up and down under the action of a sea wave. Thus, the wave energy is converted into electrical energy.

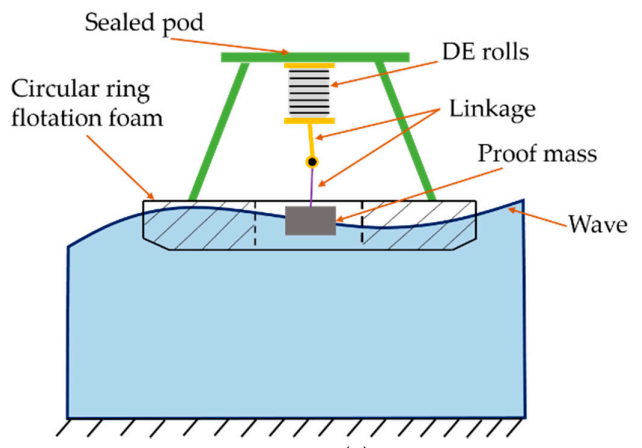

(a)

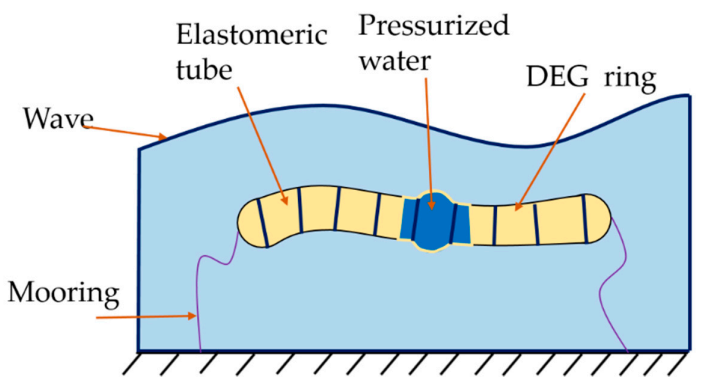

(b)

Figure 6. Cont. 


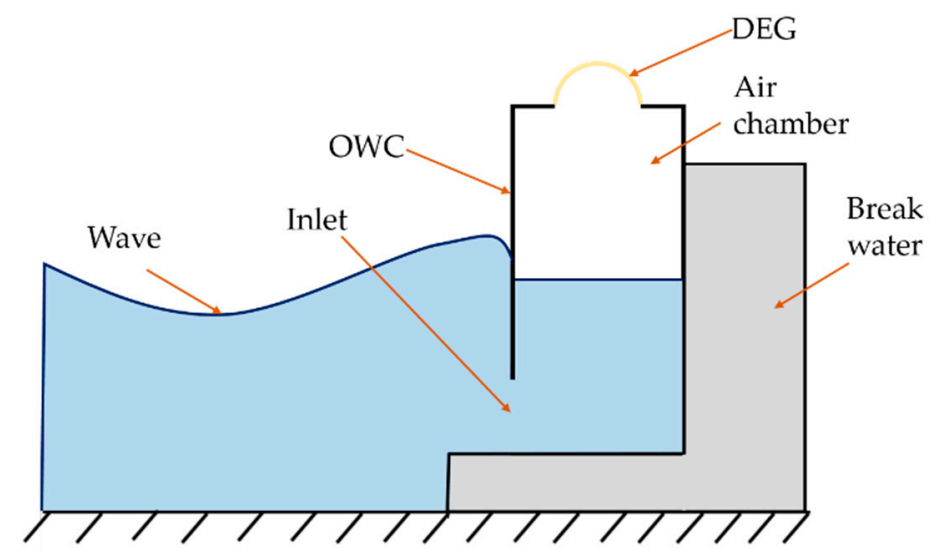

(c)

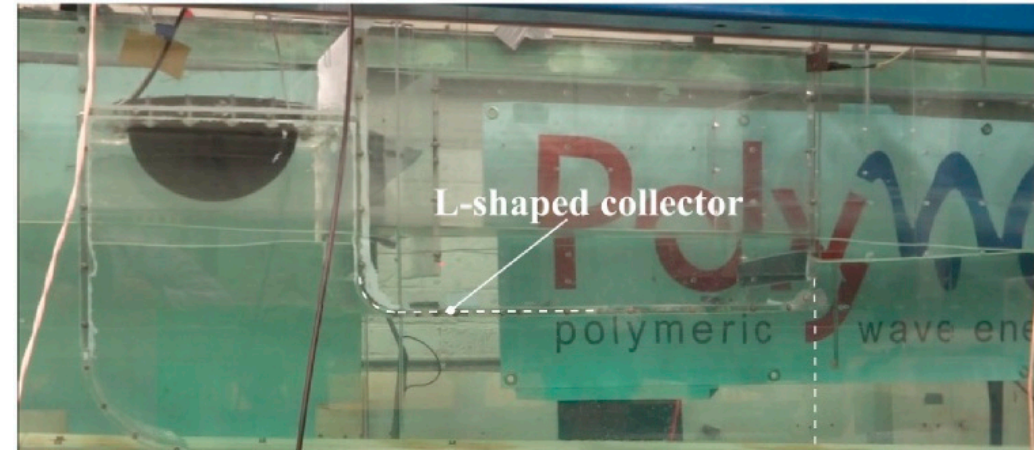

(d)

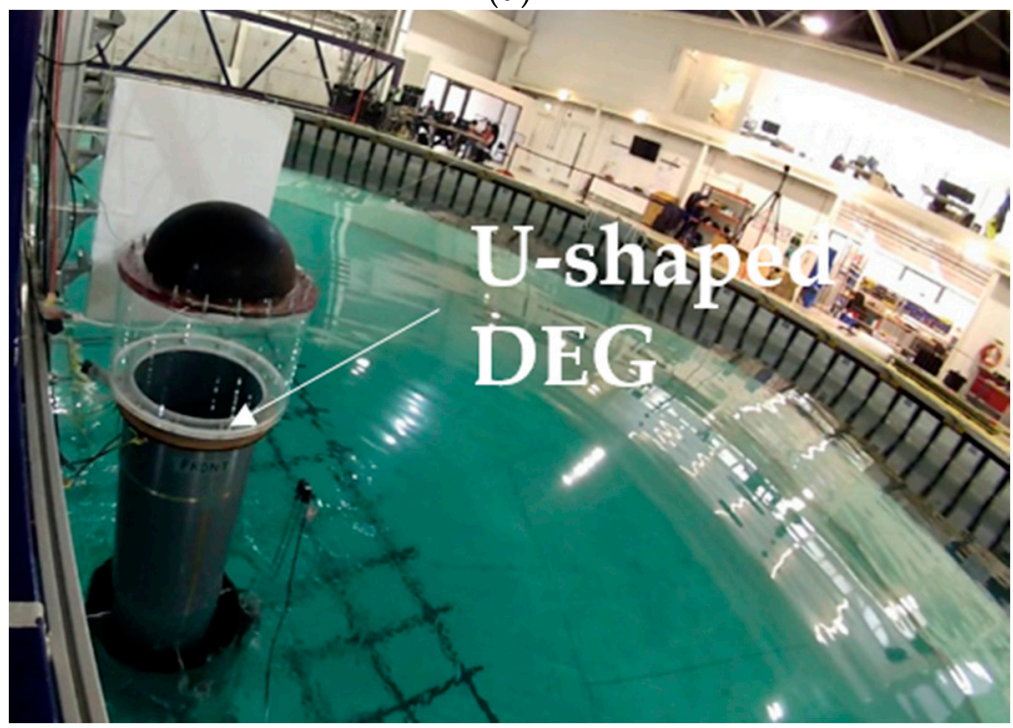

(e)

Figure 6. Cont. 


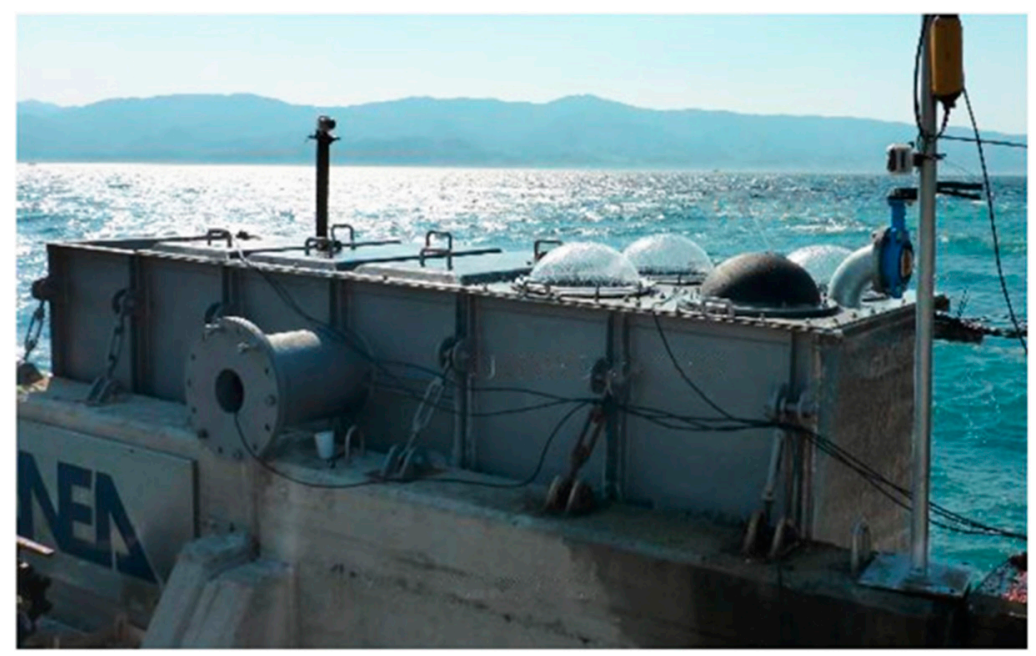

(f)

Figure 6. Some different prototypes of WEC based on DEG. (a) Illustration of buoy type WEC. (b) Illustration of WEC based on pressure standing wave. (c) Illustration of WEC based on OWC. (d) L-shaped OWC [74]. (e) U-shaped OWC. (f) U-shaped OWC tested in the sea.

The buoy-type prototype can be adapted to actual, harsh sea environments. Although the temperature inside the prototype enclosure may reach up to $55{ }^{\circ} \mathrm{C}$, with ambient humidity approaching $100 \%$, it can achieve high output performance. The peak output power of $1.2 \mathrm{~W}$ and average power of $0.25 \mathrm{~W}$ are achieved with a wave height of $10 \mathrm{~cm}$. Ultimately, the author claimed that peak power and average power could be increase to $11 \mathrm{~W}$ and $2.2 \mathrm{~W}$, respectively, if the bias voltage is raised to $6000 \mathrm{~V}$, and that average output power of $50 \mathrm{~W}$ could be achieved if the wave height is $0.5 \mathrm{~m}$. That gain would meet the power needs of a real buoy.

Kornbluh [14] also proved that the buoy DEG system can harvest wave energy to power its onboard lighting and communication systems. Output energy of $11 \mathrm{~J}$ and conversion efficiency of $78 \%$ are achieved. Additionally, the collected energy can be reduced to $12 \mathrm{~V}$, which can be used to charge a battery. A test of another buoy on a smaller device by Liu [75] obtained energy of 1.26 J and lighted 6 luminous diodes. Such performance can validate the feasibility of large-scale energy harvesting based on DEG.

Jean [76] has proposed a standing-wave tube type WEC. Its structure is similar to that shown in Figure $6 \mathrm{~b}$. The prototype is made of a long, elastomeric tubular structure, which is closed at both ends and filled with pressurized water. The DEG is rolled up into a ring multi-layer structure and distributed evenly along the axial direction of the tube. The varying pressure is applied to the tube when a wave flows through its surface, and then the tube swings up and down, changing its internal pressure. Pressure differences between the internal and external surfaces can result in deformation of the tube. Then the wave energy can be harvested.

In 2010, the concept of WEC was tested. The silicone tube was $11 \mathrm{~m}$ long and, $40 \mathrm{~cm}$ in diameter and enhanced with aramid fibers, where 25 DEG rings were slotted. Through the test, radial deformations of the ring DEG of up to $80 \%$ were measured, and output peak power of up to $2 \mathrm{~W}$ and conversion efficiency of $20 \%$ were obtained. The author declared that $100 \mathrm{~W}$ output power could be achieved if a larger electrical field is applied.

In addition to the test at sea, the numerical analytical governing equations for the standing wave tube type WEC were proposed by Babarit [77] in 2017. The governing equations for the behavior of the tube wall and flow inside and outside the tube were formulated. The motion response equation for the tube in a sea installation was deduced. The results were in good agreement with experiments. In the end, the author predicted that a few hundred kilowatts of absorbing power could be achieved if the tube was $100 \mathrm{~m}$ long. 
The oscillating water column WEC (OWC-WEC) is a promising technology for the collection of wave energy, as shown in Figure 6c. Utilizing DEG as PTO for an OWC-WEC to collect wave energy has attracted the attention of researchers. An OWC-WEC mainly consists of a semi-submerged hollow structure with an enclosed water column, air chamber, and DEG closed at the top. The water column will move with a reciprocating motion as the crest and trough of the wave enter the air chamber successively, leading to periodic pressure change inside the air chamber. Then, the DEG will inflate and shrink under the pressure difference inside and outside the air chamber. This deformation type will cause larger changes in capacitance and can be generally regarded as equibiaxial deformation.

A square OWC-WEC for VHB as PTO was first proposed by Vertechy [78]. The prototype (chamber size of $260 \mathrm{~mm} \times 285 \mathrm{~mm}$ ) was tested in a wave tank. Energy of $64 \mathrm{~mJ}$ and conversion efficiency of $1.2 \%$ were obtained in one cycle with a $0.6 \mathrm{~Hz}$ wave frequency and $0.04 \mathrm{~m}$ wave height. The author claimed that maximum output power of $76.8 \mathrm{~mW}$ would be acquired in sea testing under the same conditions, and that a large-scale system (50 times larger than the test device) could generate average power up to $68 \mathrm{~kW}$ with a $2 \mathrm{~m}$ wave height and $11.7 \mathrm{~s}$ period. The prototype demonstrated the feasibility for capturing wave energy, but dynamic response optimization of the wave was not considered in this article.

An L-shaped OWC-WEC (chamber size of $370 \mathrm{~mm} \times 370 \mathrm{~mm}$ ) to optimize the dynamic response of waves was designed by Moretti [74,79] (Figure 6d). By theoretically calculating parameters of the system, a prototype natural frequency could be set within the inlet wave frequency range, and it was possible to obtain resonance with the inlet wave. Power output of $0.87 \mathrm{~W}$, conversion efficiency of $18 \%$, and harvested energy of $0.64 \mathrm{~J}$ were achieved with a $0.7 \mathrm{~Hz}$ wave frequency and $0.09 \mathrm{~m}$ wave height. The author came up with a design method for an OWC system that reaches a resonant state, enabling more energy to be captured from a wave.

Moretti [80] has also proposed a U-shaped OWC-WEC. The prototype adds a vertical U-shaped conduit connecting the air chamber to the horizontal plane, which can adjust the OWC's natural frequency within the inlet wave frequency range. As we can see from Figure 6e, it has an axisymmetric structure. The collector has two coaxial cylinders: the inner cylinder ( $400 \mathrm{~mm}$ in diameter), enclosed by water column, and the outer cylinder (600 $\mathrm{mm}$ in diameter). By adjusting the inner and outer cylinder diameters, the OWC natural frequency can be synchronized with inlet wave frequency. Ultimately, a peak output power of $3.8 \mathrm{~W}$ was achieved in a wave tank experiment with $0.25 \mathrm{~m}$ wave height and $8.25 \mathrm{kV}$ charging voltage. The output power of this system is larger than that of DEG prototypes documented in previous literature.

Most earlier tests were conducted in wave tanks. Those experiments validated the capabilities of DEG in converting wave energy into electrical power, but did not demonstrate its performance in real sea-tests. Moretti [81] has presented a U-shaped OWC based on the theoretical design of a WEC (Figure 6f) that has been sea-tested. The U-OWC is installed in a metallic caisson that is linked to a vertical breakwater. There are four DEGs working at the same time, enabling the system to capture more energy. A butterfly valve is installed on top of the device, and is used to control the pressure in the air chamber. This prototype was manufactured with acrylic film, VHB 4905, with a final diameter of $390 \mathrm{~mm}$. The theoretical output power obtainable with this prototype is estimated to be $40-100 \mathrm{~W}$. In the article, the author focused on the purely mechanical response of the device (ignoring electrical response). Generally speaking, it was first tested by the sea in an OWC-WEC. It represents an important step toward collecting wave energy on a large scale.

Using DEG as the PTO is an economical and viable solution for wave energy harvesting. However, there are still some challenges to be overcome before utilizing DEG to collect wave energy, including: (1) Improving the service life of DEG; this is a key challenge for DEG in stable operation. At present, little investigation has focused on the service life of a DEG under electromechanical loading. (2) High viscoelasticity, electrical conductivity, and low breakdown strength (acrylic elastomer) which limit ability to capture wave energy un- 
der rough conditions. (3) Power management. Storing and utilizing the converted electrical energy are the ultimate goals. it is thus crucial to design energy management circuitry.

\section{Conclusions and Perspective}

In this paper, recent DEG developments were reviewed, considering different aspects related to materials, deformation modes, and prototypes in the field of collecting mechanical energy, including small scales such as wind energy and human motion energy, and large scales such as wave energy.

First, DE materials were investigated. The output performance of a DEG strongly depends on the properties of the DE materials, such as their break-down dielectric strength and dielectric and mechanical performance. Materials with low elastic modulus and high dielectric constant are crucially important for DEG harvesting energy.

Second, the deformation modes of a DEG have an important influence on energy harvesting. The energy gained strongly depends on deformation. The structure of a DEG is related to its deformation modes. The structural design of a DEG is also important for energy harvesting.

Third, prototypes harvesting energy from different types of mechanical sources including human motion, wind, and wave energy were reviewed. Despite their potential and the efforts made thus far, DEG has not yet been developed as commercial products and is far from practical application. Their capacity to convert mechanical energy into electrical energy has been proved. In the future, building an efficient full-scale demonstration prototype will be an urgent challenge.

Author Contributions: Writing and investigation, K.D. and K.B.; Investigation, H.C., X.X. and Y.S.; Project administration, J.T. and Y.L.; Funding acquisition, W.X. and S.E.; Supervision and review and editing. Z.X. and S.E. All authors have read and agreed to the published version of the manuscript.

Funding: This research was funded by National Natural Science Foundation of China (Grant Number 52075499) and Public Research Projects of Zhejiang Province (Grant Number LGG19E070007).

Institutional Review Board Statement: Not applicable.

Informed Consent Statement: Not applicable.

Data Availability Statement: The data that supports the findings of this study are available within the article.

Conflicts of Interest: The authors declare no conflict of interest.

\section{References}

1. Fan, K.; Zhang, Y.; Liu, H.; Cai, M.; Tan, Q. A nonlinear two-degree-of-freedom electromagnetic energy harvester for ultra-low frequency vibrations and human body motions. Renew. Energy 2019, 138, 292-302. [CrossRef]

2. Fan, F.-R.; Tian, Z.-Q.; Lin Wang, Z. Flexible triboelectric generator. Nano Energy 2012, 1, 328-334. [CrossRef]

3. Toprak, A.; Tigli, O. Piezoelectric energy harvesting: State-of-the-art and challenges. Appl. Phys. Rev. 2014, 1, 031104. [CrossRef]

4. Krupenkin, T.; Taylor, J.A. Reverse electrowetting as a new approach to high-power energy harvesting. Nat. Commun. 2011, 2, 448. [CrossRef]

5. Cottinet, P.J.; Guyomar, D.; Guiffard, B.; Putson, C.; Lebrun, L. Modeling and Experimentation on an Electrostrictive Polymer Composite for Energy Harvesting. IEEE Trans. Ultrason. Ferroelectr. Freq. Control 2010, 57, 774-784. [CrossRef]

6. Pelrine, R.; Kornbluh, R.; Pei, Q.; Joseph, J.J.S. High-Speed Electrically Actuated Elastomers with Strain Greater Than $100 \%$. Science 2000, 287, 836-839. [CrossRef] [PubMed]

7. Sadik, O.A.; Ngundi, M.; Wanekaya, A. Chemical Biological Sensors Based on Advances in Conducting Electroactive Polymers. Microchim. Acta 2003, 143, 187-194. [CrossRef]

8. Peirine, R.; Kornbluh, R.; Eckerle, J.; Jeuck, P.; Oh, S.; Pe, Q.; Stanford, S. Dielectric elastomers: Generator mode fundamentals and applications. In Proceedings of the SPIE's 8th Annual International Symposium on Smart Structures and Materials, Newport Beach, CA, USA, 16 July 2001; pp. 148-156.

9. Koh, S.J.A.; Keplinger, C.; Li, T.; Bauer, S.; Suo, Z. Dielectric Elastomer Generators: How Much Energy Can Be Converted? IEEE/ASME Trans. Mechatron. 2011, 16, 33-41. [CrossRef]

10. Shian, S.; Huang, J.; Zhu, S.; Clarke, D.R. Optimizing the electrical energy conversion cycle of dielectric elastomer generators. Adv. Mater. 2014, 26, 6617-6621. [CrossRef] 
11. Wax, S.G.; Sands, R.R. Electroactive polymer actuators and devices. In Proceedings of the 1999 Symposium on Smart Structures and Materials, SPIE, Newport Beach, CA, USA, 28 May 1999; pp. 2-10.

12. Paradiso, J.A.; Starner, T.J.I.P.C. Energy scavenging for mobile and wireless electronics. IEEE Pervasive Comput. 2005, 4, 18-27. [CrossRef]

13. Chiba, S.; Waki, M.; Masuda, K.; Ikoma, T. Current status and future prospects of electric generators using electroactive polymer artificial muscle. In Proceedings of the OCEANS'10 IEEE SYDNEY, Sydney, Australia, 24-27 May 2010.

14. Kornbluh, R.D.; Pelrine, R.; Prahlad, H.; Wong-Foy, A.; McCoy, B.; Kim, S.; Eckerle, J.; Brochu, P.; Anderson, P.I. Electroactivity in Polymeric Materials; Springer: New York, NY, USA, 2012; pp. 67-93.

15. Zhang, J.W.; Lai, Z.H.; Rao, X.X.; Zhang, C.L. Harvest rotational energy from a novel dielectric elastomer generator with crank-connecting rod mechanisms. Smart Mater. Struct. 2020, 29, 065005. [CrossRef]

16. Brochu, P.; Stoyanov, H.; Chang, R.; Niu, X.; Hu, W.; Pei, Q. Capacitive Energy Harvesting Using Highly Stretchable SiliconeCarbon Nanotube Composite Electrodes. Adv. Energy Mater. 2014, 4, 1300659. [CrossRef]

17. Graf, C.; Maas, J.; Schapeler, D. Energy harvesting cycles based on electro active polymers. In Proceedings of the SPIE Smart Structures and Materials + Nondestructive Evaluation and Health Monitoring, San Diego, CA, USA, 9 April 2010 ; p. 764217.

18. Binh, P.C.; Nam, D.N.C.; Ahn, K.K. Modeling and experimental analysis of an antagonistic energy conversion using dielectric electro-active polymers. Mechatronics 2014, 24, 1166-1177. [CrossRef]

19. Illenberger, P.; Takagi, K.; Kojima, H.; Madawala, U.K.; Anderson, I.A. A Mathematical Model for Self-Priming Circuits: Getting the Most From a Dielectric Elastomer Generator. IEEE Trans. Power Electron. 2017, 32, 6904-6912. [CrossRef]

20. Huang, J.; Shian, S.; Suo, Z.; Clarke, D.R. Dielectric elastomer generator with equi-biaxial mechanical loading for energy harvesting. In Proceedings of the SPIE Smart Structures and Materials + Nondestructive Evaluation and Health Monitoring, San Diego, CA, USA, 9 April 2013; p. 86870Q.

21. Fan, P.; Chen, H. Performance investigation of a dissipative dielectric elastomer generator by the damping model. Appl. Phys. A 2018, 124, 148-158. [CrossRef]

22. Zhou, J.Y.; Jiang, L.Y.; Khayat, R. Analysis on the energy harvesting cycle of dielectric elastomer generators for performance improvement. Europhys. Lett. 2016, 115, 27003. [CrossRef]

23. McKay, T.G.; O’Brien, B.M.; Calius, E.P.; Anderson, I.A. Soft generators using dielectric elastomers. Appl. Phys. Lett. 2011, 98, 142903. [CrossRef]

24. Wang, H.; Wang, C.; Yuan, T. On the energy conversion and efficiency of a dielectric electroactive polymer generator. Appl. Phys. Lett. 2012, 101, 33904. [CrossRef]

25. Huang, J.S.; Shian, S.; Suo, Z.G.; Clarke, D.R. Maximizing the Energy Density of Dielectric Elastomer Generators Using EquiBiaxial Loading. Adv. Funct. Mater. 2013, 23, 5056-5061. [CrossRef]

26. Liu, L.; Zhang, Z.; Liu, Y.; Leng, J. Failure modeling of folded dielectric elastomer actuator. Sci. China Phys. Mech. Astron. 2013, 57, 263-272. [CrossRef]

27. Khajehsaeid, H.; Baghshomal Azar, H. Influence of stretch and temperature on the energy density of dielectric elastomer generators. Appl. Math. Mech. 2019, 40, 1547-1560. [CrossRef]

28. Plante, J.-S.; Dubowsky, S. Large-scale failure modes of dielectric elastomer actuators. Int. J. Solids Struct. 2006, 43, 7727-7751. [CrossRef]

29. Koh, S.J.A.; Zhao, X.; Suo, Z. Maximal energy that can be converted by a dielectric elastomer generator. Appl. Phys. Lett. 2009, 94, 262902. [CrossRef]

30. Jiang, Y.; Liu, S.; Zhong, M.; Zhang, L.; Ning, N.; Tian, M. Optimizing energy harvesting performance of cone dielectric elastomer generator based on VHB elastomer. Nano Energy 2020, 71, 104606. [CrossRef]

31. Chiang Foo, C.; Cai, S.; Jin Adrian Koh, S.; Bauer, S.; Suo, Z. Model of dissipative dielectric elastomers. J. Appl. Phys. 2012, 111, 034102. [CrossRef]

32. Li, Y.; Zhou, J.; Jiang, L. The effect of nonlinear material viscosity on the energy harvesting performance of dielectric elastomer generators. J. Intell. Mater. Syst. Struct. 2020, 31, 1029-1038. [CrossRef]

33. Fan, P.; Chen, H. Optimizing the Energy Harvesting Cycle of a Dissipative Dielectric Elastomer Generator for Performance Improvement. Polymers 2018, 10, 1341. [CrossRef]

34. Chu, B.; Zhou, X.; Ren, K.; Neese, B.; Lin, M.; Wang, Q.; Bauer, F.; Zhang, Q.M. A dielectric polymer with high electric energy density and fast discharge speed. Science 2006, 313, 334-336. [CrossRef]

35. Zhang, J.; Sheng, J.; Liu, X.; Liu, L.; Zhao, J.; Chen, H. Temperature effect on electromechanical properties of polyacrylic dielectric elastomer: An experimental study. Smart Mater. Struct. 2020, 29, 047002. [CrossRef]

36. Brochu, P.; Pei, Q. Advances in dielectric elastomers for actuators and artificial muscles. Macromol. Rapid Commun. 2010, 31, 10-36. [CrossRef] [PubMed]

37. Chen, Y.; Agostini, L.; Moretti, G.; Fontana, M.; Vertechy, R. Dielectric elastomer materials for large-strain actuation and energy harvesting: A comparison between styrenic rubber, natural rubber and acrylic elastomer. Smart Mater. Struct. $2019,28,114001$. [CrossRef]

38. Madsen, F.B.; Yu, L.; Mazurek, P.; Skov, A.L. A simple method for reducing inevitable dielectric loss in high-permittivity dielectric elastomers. Smart Mater. Struct. 2016, 25, 075018. [CrossRef] 
39. Moretti, G.; Rosset, S.; Vertechy, R.; Anderson, I.; Fontana, M. A Review of Dielectric Elastomer Generator Systems. Adv. Intell. Syst. 2020, 2, 2000125. [CrossRef]

40. Michel, S.; Zhang, X.Q.; Wissler, M.; Löwe, C.; Kovacs, G. A comparison between silicone and acrylic elastomers as dielectric materials in electroactive polymer actuators. Polym. Int. 2009, 59, 391-399. [CrossRef]

41. Kaltseis, R.; Keplinger, C.; Adrian Koh, S.J.; Baumgartner, R.; Goh, Y.F.; Ng, W.H.; Kogler, A.; Tröls, A.; Foo, C.C.; Suo, Z.; et al. Natural rubber for sustainable high-power electrical energy generation. RSC Adv. 2014, 4, 27905-27913. [CrossRef]

42. Tröls, A.; Kogler, A.; Baumgartner, R.; Kaltseis, R.; Keplinger, C.; Schwödiauer, R.; Graz, I.; Bauer, S. Stretch dependence of the electrical breakdown strength and dielectric constant of dielectric elastomers. Smart Mater. Struct. 2013, 22, 104012. [CrossRef]

43. Rosset, S.; Niklaus, M.; Dubois, P.; Shea, H.R. Large-Stroke Dielectric Elastomer Actuators With Ion-Implanted Electrodes. J. Microelectromechanical Syst. 2009, 18, 1300-1308. [CrossRef]

44. Löwe, C.; Zhang, X.; Kovacs, G. Dielectric Elastomers in Actuator Technology. Adv. Eng. Mater. 2005, 7, 361-367. [CrossRef]

45. Matysek, M.; Lotz, P.; Schlaak, H.F. Lifetime Investigation of Dielectric Elastomer Stack Actuators. IEEE Trans. Dielectr. Electr. Insul. 2011, 18, 89-96. [CrossRef]

46. Moretti, G.; Righi, M.; Vertechy, R.; Fontana, M. Fabrication and Test of an Inflated Circular Diaphragm Dielectric Elastomer Generator Based on PDMS Rubber Composite. Polymers 2017, 9, 283. [CrossRef]

47. Bar-Cohen, Y.; Brochu, P.; Li, H.; Niu, X.; Pei, Q. Factors influencing the performance of dielectric elastomer energy harvesters. In Proceedings of the Electroactive Polymer Actuators and Devices (EAPAD) 2010, San Diego, CA, USA, 9 April 2010; p. 76422J.

48. Yang, D.; Xu, Y.; Ruan, M.; Xiao, Z.; Guo, W.; Wang, H.; Zhang, L. Improved electric energy density and conversion efficiency of natural rubber composites as dielectric elastomer generators. AIP Adv. 2019, 9, 025035. [CrossRef]

49. Zhang, L.; Song, F.; Lin, X.; Wang, D. High-dielectric-permittivity silicone rubbers incorporated with polydopamine-modified ceramics and their potential application as dielectric elastomer generator. Mater. Chem. Phys. 2020, 241, 122373. [CrossRef]

50. Wang, Y.; Zhou, J.-X.; Wu, X.-H.; Li, B.; Zhang, L. Energy Diagrams of Dielectric Elastomer Generators under Different Types of Deformation. Chin. Phys. Lett. 2013, 30, 066103. [CrossRef]

51. Lee, R.H.; Basuli, U.; Lyu, M.-Y.; Kim, E.S.; Nah, C. Fabrication and performance of a donut-shaped generator based on dielectric elastomer. J. Appl. Polym. Sci. 2014, 131, 40076. [CrossRef]

52. Ellingford, C.; Zhang, R.; Wemyss, A.M.; Zhang, Y.; Brown, O.B.; Zhou, H.; Keogh, P.; Bowen, C.; Wan, C. Self-Healing Dielectric Elastomers for Damage-Tolerant Actuation and Energy Harvesting. ACS Appl. Mater. Interfaces 2020, 12, 7595-7604. [CrossRef] [PubMed]

53. Sasso, M.; Palmieri, G.; Chiappini, G.; Amodio, D. Characterization of hyperelastic rubber-like materials by biaxial and uniaxial stretching tests based on optical methods. Polym. Test. 2008, 27, 995-1004. [CrossRef]

54. Wang, Y.; Chen, B.; Bai, Y.; Wang, H.; Zhou, J. Actuating dielectric elastomers in pure shear deformation by elastomeric conductors. Appl. Phys. Lett. 2014, 104, 064101. [CrossRef]

55. Song, Z.-Q.; Ohyama, K.; Shian, S.; Clarke, D.R.; Zhu, S. Power generation performance of dielectric elastomer generator with laterally-constrained configuration. Smart Mater. Struct. 2020, 29, 015018. [CrossRef]

56. Bar-Cohen, Y.; Brochu, P.; Stoyanov, H.; Niu, X.; Pei, Q. Energy conversion efficiency of dielectric elastomer energy harvesters under pure shear strain conditions. In Proceedings of the Electroactive Polymer Actuators and Devices (EAPAD) 2012, San Diego, CA, USA, 3 April 2012; p. 83401W.

57. Kaltseis, R.; Keplinger, C.; Baumgartner, R.; Kaltenbrunner, M.; Li, T.; Mächler, P.; Schwödiauer, R.; Suo, Z.; Bauer, S. Method for measuring energy generation and efficiency of dielectric elastomer generators. Appl. Phys. Lett. 2011, 99, 162904. [CrossRef]

58. McKay, T.G.; Rosset, S.; Anderson, I.A.; Shea, H. Dielectric elastomer generators that stack up. Smart Mater. Struct. 2015, 24, 015014. [CrossRef]

59. Zhang, C.L.; Lai, Z.H.; Rao, X.X.; Zhang, J.W.; Yurchenko, D. Energy harvesting from a novel contact-type dielectric elastomer generator. Energy Convers. Manage. 2020, 205, 112351. [CrossRef]

60. Fan, P.; Zhu, L.; Zhu, Z.; Chen, H.; Chen, W.; Hu, H. Predicting energy harvesting performance of a random nonlinear dielectric elastomer pendulum. Appl. Energy 2021, 289, 116696. [CrossRef]

61. Yurchenko, D.; Val, D.V.; Lai, Z.H.; Gu, G.; Thomson, G. Energy harvesting from a DE-based dynamic vibro-impact system. Smart Mater. Struct. 2017, 26, 105001. [CrossRef]

62. Lai, Z.H.; Thomson, G.; Yurchenko, D.; Val, D.V.; Rodgers, E. On energy harvesting from a vibro-impact oscillator with dielectric membranes. Mech. Syst. Sig. Process. 2018, 107, 105-121. [CrossRef]

63. Yurchenko, D.; Lai, Z.H.; Thomson, G.; Val, D.V.; Bobryk, R.V. Parametric study of a novel vibro-impact energy harvesting system with dielectric elastomer. Appl. Energy 2017, 208, 456-470. [CrossRef]

64. Thomson, G.; Yurchenko, D.; Val, D.V.; Zhang, Z. Predicting energy output of a stochastic nonlinear dielectric elastomer generator. Energy Convers. Manage. 2019, 196, 1445-1452. [CrossRef]

65. Zhang, C.L.; Lai, Z.H.; Li, M.Q.; Yurchenko, D. Wind energy harvesting from a conventional turbine structure with an embedded vibro-impact dielectric elastomer generator. J. Sound Vib. 2020, 487, 115616. [CrossRef]

66. Lai, Z.H.; Wang, J.L.; Zhang, C.L.; Zhang, G.Q.; Yurchenko, D. Harvest wind energy from a vibro-impact DEG embedded into a bluff body. Energy Convers. Manage. 2019, 199, 111993. [CrossRef] 
67. Goudar, V.; Wendt, J.B.; Potkonjak, M.; Ren, Z.; Brochu, P.; Pei, Q. Leveraging human gait characteristics towards self-sustained operation of low-power mobile devices. In Proceedings of the IEEE World Forum on Internet of Things (WF-IoT), Seoul, Korea, 6-8 March 2014; pp. 468-473.

68. Bar-Cohen, Y.; Jean-Mistral, C.; Basrour, S.; Chaillout, J.-J. Dielectric polymer: Scavenging energy from human motion. In Proceedings of the SPIE Smart Structures and Materials + Nondestructive Evaluation and Health Monitoring, San Diego, CA, USA, 10 April 2008; p. 692716.

69. Jean-Mistral, C.; Basrour, S. Scavenging energy from human motion with tubular dielectric polymer. In Proceedings of the SPIE Smart Structures and Materials + Nondestructive Evaluation and Health Monitoring, San Diego, CA, USA, 10 April 2008; p. 764209 .

70. Slade, J.R.; Bowman, J.; Kornbluh, R. Bio-kinetic energy harvesting using electroactive polymers. In Proceedings of the SPIE Defense, Security, and Sensing, Baltimore, MD, USA, 21 May 2012; p. 83830R.

71. Kornbluh, R.; Pelrine, R.; Pei, Q.; Heydt, R.; Stanford, S.; Oh, S.; Eckerle, J. Electroelastomers: Applications of dielectric elastomer transducers for actuation, generation, and smart structures. In Proceedings of the SPIE's 9th Annual International Symposium on Smart Structures and Materials, San Diego, CA, USA, 9 July 2002; pp. 257-270.

72. Savage, N. IEEE Spectrum, Deformable Acrylics Could Turn Human Motion into Electricity. Available online: https://spectrum. ieee.org/green-tech/fuel-cells/squishy-power-generators (accessed on 18 December 2012).

73. Bar-Cohen, Y.; Chiba, S.; Waki, M.; Kornbluh, R.; Pelrine, R. Innovative power generators for energy harvesting using electroactive polymer artificial muscles. In Proceedings of the SPIE Smart Structures and Materials + Nondestructive Evaluation and Health Monitoring, San Diego, CA, USA, 10 April 2008; 2008; p. 692715.

74. Moretti, G.; Santos Herran, M.; Forehand, D.; Alves, M.; Jeffrey, H.; Vertechy, R.; Fontana, M. Advances in the development of dielectric elastomer generators for wave energy conversion. Renew. Sustain. Energy Rev. 2020, 117, 109430. [CrossRef]

75. Liu, Y.; Liu, L.; Zhang, Z.; Jiao, Y.; Sun, S.; Leng, J. Analysis and manufacture of an energy harvester based on a Mooney-Rivlintype dielectric elastomer. Europhys. Lett. 2010, 90, 36004. [CrossRef]

76. Jean, P.; Wattez, A.; Ardoise, G.; Melis, C.; Van Kessel, R.; Fourmon, A.; Barrabino, E.; Heemskerk, J.; Queau, J.P. Standing wave tube electro active polymer wave energy converter. In Proceedings of the SPIE Smart Structures and Materials + Nondestructive Evaluation and Health Monitoring, San Diego, CA, USA, 5 April 2012; p. 83400C.

77. Babarit, A.; Singh, J.; Mélis, C.; Wattez, A.; Jean, P. A linear numerical model for analysing the hydroelastic response of a flexible electroactive wave energy converter. J. Fluids Struct. 2017, 74, 356-384. [CrossRef]

78. Vertechy, R.; Fontana, M.; Rosati Papini, G.P.; Forehand, D. In-tank tests of a dielectric elastomer generator for wave energy harvesting. In Proceedings of the SPIE Smart Structures and Materials + Nondestructive Evaluation and Health Monitoring, San Diego, CA, USA, 8 March 2014; p. 90561G.

79. Moretti, G.; Papini, G.P.R.; Righi, M.; Forehand, D.; Ingram, D.; Vertechy, R.; Fontana, M. Resonant wave energy harvester based on dielectric elastomer generator. Smart Mater. Struct. 2018, 27, 035015. [CrossRef]

80. Moretti, G.; Rosati Papini, G.P.; Daniele, L.; Forehand, D.; Ingram, D.; Vertechy, R.; Fontana, M. Modelling and testing of a wave energy converter based on dielectric elastomer generators. Proc. R. Soc. A 2019, 475, 20180566. [CrossRef] [PubMed]

81. Moretti, G.; Malara, G.; Scialò, A.; Daniele, L.; Romolo, A.; Vertechy, R.; Fontana, M.; Arena, F. Modelling and field testing of a breakwater-integrated U-OWC wave energy converter with dielectric elastomer generator. Renew. Energy 2020, 146, 628-642. [CrossRef] 